\title{
Research on the Training Mode of Film and Television Cultural Talents under the Background of Barrier Free Information Development
}

\author{
Can Li, Huaiqiu Gu*, Qingqin Zhang \\ Shanghai Publishing and Printing College, Shanghai Jian Qiao University, Shanghai, China \\ Email: ^65294056@qq.com
}

How to cite this paper: Li, C., Gu, H. Q., \& Zhang, Q. Q. (2022). Research on the Training Mode of Film and Television Cultural Talents under the Background of Barrier Free Information Development. Art and Design Review, 10, 136-143.

https://doi.org/10.4236/adr.2022.101010

Received: December 8, 2021

Accepted: February 25, 2022

Published: February 28, 2022

Copyright $\odot 2022$ by author(s) and Scientific Research Publishing Inc. This work is licensed under the Creative Commons Attribution International License (CC BY 4.0).

http://creativecommons.org/licenses/by/4.0/

\section{(C) (i) Open Access}

\begin{abstract}
The 21 st century is a rapidly developing information age. Through the combination of art and technology, barrier free cultural content can not only remove the obstacles for barrier people to accept cultural content, but also broaden the scope of online barrier free audio-visual communication, but also help visually impaired people better understand cultural achievements through oral images and promote the social integration of barrier groups. However, at present, the supply of audio-visual works of barrier free culture is relatively small, and the production level of barrier free cultural content produced for barrier groups is not high. The most important thing is the extreme lack of professionals for barrier free film and television IP creative publishing and distribution. Facing this situation, the practice of some European universities has brought better enlightenment, and also provided reference for the cultivation of barrier free film and television cultural talents in Chinese universities.
\end{abstract}

\section{Keywords}

Barrier Free Film and Television, Personnel Training, Audio Description

\section{Introduction}

The 21st century is a rapidly developing information age. A large number of information products have been bred. The accelerated development of the Internet has created countless connections between people. However, when we cover our eyes or ears, we will find that some people are in a "lost contact" state, including ${ }^{\star}$ Corresponding author. 
information culture barrier groups. In 2020, the guiding opinions on promoting information accessibility jointly issued by the ministry of industry and information technology and the China Disabled Persons' Federation clearly pointed out that information accessibility refers to making up for the differences in physical function and environment through information means, so that anyone (whether healthy or disabled, young or old) can have equal, convenient and safe access to information interact, use information and enjoy cultural communication. In the era of Internet digital media communication, film and television cultural works should be able to better show their spiritual strength and play their own functions through new technologies and digital media. The term "accessibility" is translated from accessibility, which means that anyone can have equal, convenient and barrier free access to and use of information under any circumstances. In the early 1960s, the concept of "accessibility" began to take shape. It began with the "normalization principle" put forward by Danish scholar N.E. BankMikkelsen, which advocates that every person with physical and mental disabilities should live and receive education with normal people in their culture as much as possible ( $\mathrm{Li}, 2017)$. Oral image is a method of converting visual picture into sound description (Gao, 2020). Achieve the artistic transmission of barrier free audio-visual entertainment works through oral images, further tap the potential of the deep combination of integrated media and the media use needs of disabled people, use the large network woven by media integration to capture those special people who lost contact in cultural communication, and build a "blind path" for them under the digital media network environment.

\subsection{Insufficient Creation of Cultural Content IP for Visually Impaired People}

Compared with the needs of the visually impaired, the current supply of audio-visual works of barrier free culture is relatively small. Due to the lack of market incentives, barrier free cultural IP has not formed an industrial chain. It is only promoted by the government or public welfare organizations. It cannot form a scale from capital investment to mass production, which leads to the shortage of audio-visual content. With the development of the Internet, watching movies online has become a trend. The same is true for people with audio-visual disabilities. With the development of information accessibility technology, more and more people can surf the Internet and like to surf the Internet. Therefore, how to make people with audio-visual disabilities watch barrier free cultural content on the Internet is also a problem we need to explore. At present, the development of barrier free film and television is still in the offline stage, and online services are still under exploration, but many people have this demand.

\subsection{The Production Level and Interpretation Quality Are Not High}

The development of an excellent barrier free film and television work requires a 
high professional level. Especially for the barrier free cultural content made for visually impaired people, it is necessary to convert the visual symbols on the picture into sound symbols, that is, it should be fast, accurate and vivid. This process is quite complex. In the view of Taiwan scholar Zhao ya, the process of oral images of the blind is not only a process of translation and reproduction, but also a process of re coding and re creation. From the film and television text to the visually impaired audience needs the intermediary of the oral image writer (narrator). The oral image writer acts as a communication intermediary. It needs to interpret and re encode the film part to convey the meaning of the picture.

At present, most of the producers of barrier free film and television works in China are volunteers, and a few are professional film and television producers. This makes the quality of barrier free film and television cannot be guaranteed. Because all the people involved in the production of barrier free culture are public welfare, part-time and amateur, which naturally cannot guarantee the quality of the film. Many barrier free cultures I have seen are actually barrier free, because if we cover our eyes and "see", a lot of information is incomprehensible. This shows that there is still much room for improvement in our voice interpretation.

\subsection{Lack of Barrier Free Film and Television Production Personnel Training}

There is a great lack of professionals in barrier free film and television IP creative publishing and distribution. Barrier free culture involves three categories: film, broadcasting and publishing. Although they belong to the same cultural category, they have their own characteristics. There is a great lack of artistic talents integrating the expertise of the three categories, especially those who are familiar with the living habits and appreciation characteristics of the visually impaired, which is a short board in the construction and communication of barrier free film and television. In Europe, the oral image of telling the picture content for the disabled group is a professional, and the personnel need to be trained or studied. The reference of this model provides a reference for the training of barrier free film and television cultural talents in domestic colleges and universities.

\section{The Cultivation of Barrier Free Film and Television Production Talents in Europe}

\subsection{Definition of Barrier Free Film and Television Production}

Barrier free film and television production (AVT, audiovisual translation) is a special translation activity developed with the translation of films and cinema programs at the end of the 19th century. It can be traced back to the inserted subtitles in the silent film era. So far, it has a history of more than 100 years. People first used "film translation" to refer to "barrier free film and television 
production" (Wang, 2019).

With the development of technology, translation practice and research connotation, "barrier free film and television production" has experienced several changes in terms of "film translation", "language transfer", "adaptation", "screen translation" and "multimedia translation". Among these terms, "barrier free film and television production" has significant advantages in the scope, professionalism and applicability of cultural products it covers. It is a general term that "can cover all new technology development and industry practice". It does not simply focus on the type of program or broadcasting place, but emphasizes the communication channel between the translated work and the audience (Dong, 2012).

Orer defined the scope and qualitative characteristics of barrier free film and television production in topic in audio translation: "barrier free film and television production not only includes all translation or multi symbol conversion used for work production (or subsequent production) in any media and form, but also includes media barrier free communication: that is, subtitles or oral images of hearing-impaired people serving people with audio-visual disabilities". This definition comprehensively summarizes the category and internal essential characteristics of barrier free film and television production, and is the most authoritative description of barrier free film and television production at present. Barrier free film and television production includes subtitle, dubbing, voice-over, SDHH (subtitle for the dead and hard of hearing), AD (audio description), live and subtitle. The latter three modes are collectively referred to as media accessibility. The communication carriers of barrier free film and television production products mainly include: film and television dramas, documentaries, cartoons, open classes, promotional films, variety shows, reality shows and interview programs.

\subsection{Learn from Foreign Audio-Visual Translation Talent Training Ideas to Promote the Accumulation of Barrier Free Film and Television Talents}

In 2014, the master of translation (MTI) program of Communication University of China was approved, setting the direction of "audio-visual translation" in the part of English translation. However, at the level of talent training, there are many problems in domestic colleges and universities, such as single curriculum, only unsystematic training, resulting in the audio-visual translation ability and level of trained talents far from meeting the needs of social development and market. In fact, the film and television translation courses offered by most colleges and universities offering translation majors are only part of the cultivation of translation ability.

Due to the restriction of teachers, it is impossible to carry out systematic training for film and television translators (Tan, 2016). In order to improve the ability of audio-visual translators and cultivate audio-visual translation talents, it is necessary to formulate a reasonable training scheme for audio-visual transla- 
tion talents in MTI education.

Some well-known universities in Europe have accumulated rich experience in the training of audio-visual translation talents. The author investigated several well-known universities in Europe. After investigation and analysis, it is found that the audio-visual translation courses of five representative universities in Europe show several common characteristics: in terms of training objectives, they focus on improving audio-visual translation skills and cultivating high-level and professional talents to meet the needs of the rapidly developing audio-visual translation market. In terms of course content, theoretical teaching is combined with practical operation, focusing on practical practice; provide students with opportunities to contact industry experts and participate in real professional practice; pay attention to the study and application of translation technology; cultivate students' professional awareness and knowledge of laws and contracts that affect translators.

The audio-visual translation master's course offered by the department of media, culture and language of rohamston university in London is an international leading course. The audio-visual translation master is the European Masters in translation recognized by the European Commission. Below, the author will systematically introduce the four aspects of the college's audio-visual translation talent training objectives, career trends, equipment allocation, teachers, course content and completion assessment, so as to provide a reference for the cultivation of barrier free film and television talents in China.

\subsubsection{Training Objectives}

The course is intended for students who are bilingual and interested in language translation, as well as native English speakers. Cultivate high-level audio-visual translation talents by teaching various audio-visual translation professional practices, such as subtitle translation, media localization, film dubbing, voice over and media barrier free communication (subtitles, oral images and real-time subtitles for the deaf), so that students can not only obtain the necessary skills for translation professional practice in the 21 st century, such as learning how to do subtitle translation, how to dub and voice over, how to provide audio-visual services for those with audio-visual disabilities and master important translation theoretical knowledge.

\subsubsection{Career Trends}

Students can apply the skills learned in class to professional practice, continue to learn new skills and add chips to their resume. In addition, the course is career oriented, providing students with employment opportunities in the audio-visual industry in the UK and abroad, and signing employment contracts.

\subsubsection{Faculty}

The project teachers are experts in the professional field of barrier free audio-visual translation, and have an influence on the policy formulation of institutions (such as the British communications authority). These experts bring their 
first-hand professional experience into the classroom, which means that students can benefit a lot from cutting-edge research and practice.

\subsubsection{Course Content}

It involves theory and practice, including compulsory module and elective module. It also involves media accessibility. In (but not limited to) EU countries, the new legislation requires broadcasting and subtitle companies to subtitle all media content (including pre recorded or live programs) for deaf or hearing impaired audiences. Translators can produce standardized subtitles for people with hearing impairment; students can learn to familiarize themselves with subtitle audience, subtitle characteristics and voice recognition software by means of real-time subtitles of voice recognition (retelling), which is the preferred way to add subtitles to live programs; audio visual description for people with visual impairment. Through practical exercises, students can increase their understanding of the special needs of people with audio-visual disabilities and enhance the skills of media barrier free communication.

\section{Practice of SPPC in the Cultivation of Barrier Free Film and Television Cultural Talents}

China's colleges and universities began the training of barrier free professionals in the late 1980s. In the past 30 years, the training process of barrier free professionals has developed slowly. At present, barrier free teaching and research activities are mainly distributed in first-class disciplines such as architecture, computer science and technology. At present, there are no special barrier free undergraduate majors in colleges and universities in China. In terms of high-level talent training, Beijing Union University took the lead in setting up a master's program of information accessibility assistive technology for secondary disciplines outside the directory under the primary discipline of software engineering in 2012; since 2014, Zhejiang University has enrolled graduate students in the research direction of information accessibility in the first-class discipline of computer science and technology, and has explored the cultivation of high-level talents with information accessibility for many years. In 2019, Shanghai Publishing and Printing College also opened the specialty of sound technology (Image Archives Technology), including oral image, audio-visual translation and other courses, with remarkable results.

\subsection{Curriculum Construction}

Relying on the image archives technology studio, Shanghai Publishing and Printing College initially established the oral image discipline learning and training module. Module 1: thinking, innovation and Translation: creative translation in innovative industries. Module 2: vocational skills of oral video. It aims to cultivate professional translation and cross-cultural communication talents, make students aware of the market demand of audio-visual language service industry, master audio-visual language translation skills and enhance their employability. 
Module 3: dubbing and voice over. Pay attention to the translation of texts and programs consumed in the audio-visual and media world, and help students improve their dubbing and voice over skills of texts with different registers and styles. Module 4: media barrier free communication. Module 5: barrier free communication film production: theory and practice. The module aims to integrate audio-visual translation and media accessibility into the context of film production, explore relevant elements from film production, help students understand the essence of movie language, edit audio-visual texts, and become excellent audiovisual interpreters.

\subsection{Integration of Industry and Education}

The film and Television Art Department of our university, together with Shanghai film review society and Shanghai Yiyou Information Technology Co., Ltd., jointly developed and promoted the barrier free film project, and jointly studied and implemented the system structure of "school enterprise combination, task driving, project leading and scientific research support" under the deep integration of industry, university and research. A deep social public welfare cooperation and promotion model of joint, perfect, counterpart, evaluation and development has been preliminarily established.

Since the establishment of the barrier free film production talent project, under the special circumstances of the epidemic situation, it still adheres to online training, communication and production. It has successively carried out 12 lectures on the nail group and tencent conference platform, with 30 participants per capita and hundreds of production exchanges. It has still efficiently completed the barrier free version production of 12 episodes of online dramas and 2 films in a short time. Among them, Jia Zhangke's film "mountain and river old man" is also equipped with Mandarin version and sign language version. This public welfare project is a teaching reform driven by real tasks, and has established many influential art brand projects in the practice of art specialty projects in Shanghai higher vocational colleges, including school enterprise cooperation, school government cooperation, school bank cooperation and so on.

\section{Conclusion}

With the rapid development of globalization, informatization and barrier free information, people's channels and methods of obtaining, receiving and disseminating information have changed, and audio-visual products are one of the main ways for the world to understand China. Through the combination of art and technology, barrier free cultural content can not only remove the obstacles for visually impaired people to accept cultural content, at the same time, broaden the scope of online barrier free audio-visual communication, and help visually impaired people better understand cultural achievements and have a dialogue with the public through oral images. Therefore, colleges and universities in China also need to carry out barrier free film and television production teach- 
ing and training to cultivate professional and applied barrier free film and television production talents. In this training process, I can learn from the barrier free film and television production talent training concept of foreign colleges and universities, and set up barrier free film and television production courses in combination with national strategy, market demand and the actual situation of colleges and universities. In terms of teachers, we can hire domestic and foreign barrier free film and television production experts and professional translators with barrier free film and television production experience to give lectures or carry out a series of special academic lectures; in terms of teaching methods, the combination of offline and online teaching methods such as case explanation, simulation practice, special lectures and online forums can be adopted. In addition, cooperating with domestic radio and television publishing bureaus, film and television companies and studios to build a student employment practice platform; we will further promote international cooperation in running schools and jointly train excellent barrier free film and television production talents with well-known foreign colleges and universities.

\section{Acknowledgements}

Supported by 2021 Annual Project of Shanghai Social Science Planning “Temperature and Speed in Shanghai: Research on Barrier Free Film and Television Cultural Communication under the Background of Digital Media Development" (Item Number: 2021BXW003).

\section{Conflicts of Interest}

The authors declare no conflicts of interest regarding the publication of this paper.

\section{References}

Dong, H. Y. (2012). Research and Teaching of Barrier Free Film and Television Production. Shanghai Translation, 53-57.

Wang, H. F. (2019). The Training Scheme of Audio-Visual Translation Talents in European Universities and Its Enlightenment. Future and Development, 49.

Gao, X. H. (2020). Obstacles and Breakthroughs: An Analysis of the Current Situation of Barrier Free Film Industry in China. Communication University of China Press, Research on News Communication in China, 23.

Li, D. X. (2017). Concept and Level Hearing and Seeing-A Study on Barrier Free Communication of Film and Television Media. Zhejiang Academic Journal, 45.

Tan, J. H. (2016). Interdisciplinary Exploration Space of Film and Television Translation Research . Teaching Management, Chinese Translators Journal, 59-63. 